\title{
Relationship between agricultural pesticides and the diet of riparian spiders in the field
}

\author{
Nadin Graf ${ }^{*} \mathbb{0}$, Karina P. Battes ${ }^{3}$, Mirela Cimpean ${ }^{3}$, Martin H. Entling ${ }^{1}$, Katharina Frisch', Moritz Link? \\ Andreas Scharmüller ${ }^{1}$, Verena C. Schreiner ${ }^{1}$, Eduard Szöcs ${ }^{1}$, Jochen P. Zubrod ${ }^{1,2}$ and Ralf B. Schäfer ${ }^{1 *}$ (D)
}

\begin{abstract}
Background: Examining the effects of pesticides is difficult in regions such as Western Europe because of the relatively ubiquitous use of agrochemicals and the lack of unaffected areas. To study a wide gradient of agrochemical stress, we conducted a study in Central Romania, where traditional agriculture, which is assumed to use less agrochemicals, exists adjacent to intensive agriculture. We investigated potential effects of land use related stressors including pesticides on aquatic-terrestrial predator-prey relationships using stable isotope analysis. Therefore, we sampled spiders, as well as their aquatic and terrestrial prey along streams with a pesticide pollution gradient and determined spider and prey stable carbon and nitrogen signals.

Results: Aquatic prey contributed $40.8-55.4 \%$ to the diet of the orb web weaving spider Tetragnatha sp. and 34.0$53.0 \%$ to the diet of the ground-hunting Pardosa sp. The biomass of potential aquatic prey increased along a gradient of increasing riparian habitat conditions and water quality and decreasing agriculture (e.g. arable land) in the catchment. The proportion of aquatic prey in the orb web weavers diet responded positively to the biomass of potential aquatic prey and negatively to this gradient. Increasing potential prey biomass resulted in an increasing proportion of aquatic prey for the orb web weaver. The proportion of aquatic prey in the ground hunters diet increased with instream pesticide toxicity and along a gradient of increasing pastoralism in the catchment as well as increasing riparian habitat and water quality.

Conclusion: The diet of two riparian predators responded to complex gradients of catchment land use, stream and riparian habitat quality as well as to in-stream pesticide toxicity. The responses to the different environmental variables can be attributed to direct (e.g. change in spider community) and indirect (e.g. changes in aquatic prey and terrestrial prey) effects. Future manipulative field studies or experiments on aquatic-terrestrial food webs are required to examine the causality of our findings and should also consider the quality of prey organisms to foster mechanistic understanding of cross-ecosystem effects.
\end{abstract}

Keywords: Stable isotopes, Pesticide toxicity, Food chain, Aquatic-terrestrial linkages, Subsidies, Ecosystems, Streams, Romania, Invertebrates

\section{Background}

Emerging aquatic insects are an important prey source for riparian predators, subsidising the terrestrial ecosystem with energy and essential nutrients [1-3] and

\footnotetext{
*Correspondence: graf-nadin@uni-landau.de; schaefer-ralf@uni-landau.de

1 iES Landau, Institute for Environmental Sciences, University Koblenz-

Landau, Fortstraße 7, 76829 Landau, Germany

Full list of author information is available at the end of the article
}

constitute a major part of the diet of riparian spiders, which in turn are a prey resource for terrestrial organisms such as birds [4].

The magnitude of aquatic emergence depends not only on factors such as climate [5,6], geomorphology of the catchment [7, 8], cover of riparian vegetation [9] and water flow [10] ], but also on stressors related to agricultural land use, such as excessive nutrient, sediment and pesticide inputs [11-13]. Altered aquatic insect

\section{Springer Open}

(c) The Author(s) 2020. This article is licensed under a Creative Commons Attribution 4.0 International License, which permits use, sharing, adaptation, distribution and reproduction in any medium or format, as long as you give appropriate credit to the original author(s) and the source, provide a link to the Creative Commons licence, and indicate if changes were made. The images or other third party material in this article are included in the article's Creative Commons licence, unless indicated otherwise in a credit line to the material. If material is not included in the article's Creative Commons licence and your intended use is not permitted by statutory regulation or exceeds the permitted use, you will need to obtain permission directly from the copyright holder. To view a copy of this licence, visit http://creativeco mmons.org/licenses/by/4.0/. 
emergence through changes in land use may subsequently affect the diet of terrestrial predators and in turn components of the terrestrial food web. Several studies showed that environmental conditions including stressors alter insect emergence from streams and in turn the diet of riparian predators (e.g. birds) consuming aquatic prey $[4,11,14]$. Hence, land use related stressors can affect the aquatic-terrestrial coupling with effects propagating into terrestrial food webs.

Riparian spiders represent a group of predators that often relies on terrestrial and aquatic and aquatic ecosystems and to detect potential cross-ecosystem effects. Higher aquatic prey availability increases the aquatic prey contribution to spider diet $[15,16]$ and can lead to a higher spider density in riparian areas [2, 16, 17]. Conversely, a lower aquatic prey availability by stressors can lead to a reduction of riparian spiders. For example, metal pollution reduced aquatic prey availability and in turn density, composition and abundance of riparian spiders $[16,18]$.

Pesticides have been recognised as an important stressor for aquatic and terrestrial ecosystems in agricultural landscapes. However, studies on the effects of pesticides have largely been limited to either aquatic [19] or terrestrial $[20,21]$ ecosystems in the agricultural landscape ignoring potential consequences for crossecosystem food webs [22]. Previous studies that considered cross-ecosystem effects have mainly focused on agricultural land use as a general stressor [11, 12, 14]; whereas, to our knowledge, studies of the specific effects of pesticides are lacking. Such studies would improve our understanding of aquatic terrestrial linkages in general and of the direct and indirect effects and aquatic ecosystems and to detect potential cross-ecosystem effects. With respect to riparian spiders, a study by Graf et al. [23] found a reduced abundance and species richness, as well as changed community composition in response to in-stream pesticide toxicity. It remained uncertain to which extent this response was a direct effect of pesticide toxicity in the terrestrial habitat and an indirect effect through altered terrestrial and aquatic prey emergence, the latter constituting a cross-ecosystem effect. An analysis of the diet of riparian spiders would provide insights into potential mechanisms of the response of spiders to in-stream pesticide toxicity.

We conducted an explorative field study on how the biomass of potential aquatic prey and the diet of riparian spiders respond to agricultural stressors with a particular emphasis on pesticide toxicity. The study was conducted in Central Romania because this region is characterised by traditional, low-intensity agriculture that persists next to areas with high-intensity agriculture [24, 25], potentially allowing to capture a wider gradient of in-stream pesticide toxicity than in landscapes predominantly characterised by high-intensity agriculture, as for example in Western Europe [19]. In a previous study, we found that changes in riparian spider communities correlated with in-stream pesticide toxicity [23]. Here, we focus on the response of the diet of two riparian spiders, with different foraging strategies (a web weaver and a ground hunter), to in-stream pesticide toxicity and other stream variables, to identify potential changes in the linkage between aquatic and terrestrial food webs. We expected that the diet responds to pesticide toxicity because it is well known that pesticides change the composition of aquatic invertebrate communities and consequently the composition of potential prey biomass [26]. Given that several agricultural stressors often co-occur (e.g. excessive nutrients, pesticides), with potentially different effect directions on the potential prey biomass (e.g. a recent meta-analysis attributed the increase of the aquatic proportion in the spider diet with agricultural land use nutrients can increase biomass to nutrients increasing the available aquatic biomass [27], pesticides can decrease the biomass of sensitive organisms but increase the biomass of tolerant organisms with unknown total effect), we did not formulate a specific hypothesis on the direction of the response of the spider diet. However, we expected a higher proportion of aquatic prey in the diet of the web weaving spider due to its stronger reliance on streams.

\section{Materials and methods}

\section{Study area and sample site selection}

The study was conducted in Central Romania around Cluj-Napoca. The region was selected because traditional agricultural land use prevails in this part of Romania besides industrialised agriculture. Traditional agriculture was characterised by fields subdivided into many small parcels and by reliance on human and animal labour and regarded as low-intensity agriculture, in contrast to industrialised agriculture with large field sizes and reliance on heavy machinery. The landscape in which low-intensity agriculture is conducted has been reported as a mosaic of arable fields (15\% cover, lowintensity agriculture), settlements and other minor land uses ( $15 \%$ cover), deciduous forests ( $30 \%$ cover) and pastures (40\% cover, low-intensity grazing and mowing) [24]. In total we selected 19 sites where we sampled spiders and their potential prey, in-stream pesticides and monitored several other environmental parameters (Fig. 1, see Additional file 1: Table S1). The fields in the upstream catchments of the streams comprised high and lowintensity agricultural fields that were expected to be associated with high and low pesticide use, respectively. They were selected to cover a gradient of high-intensity to 


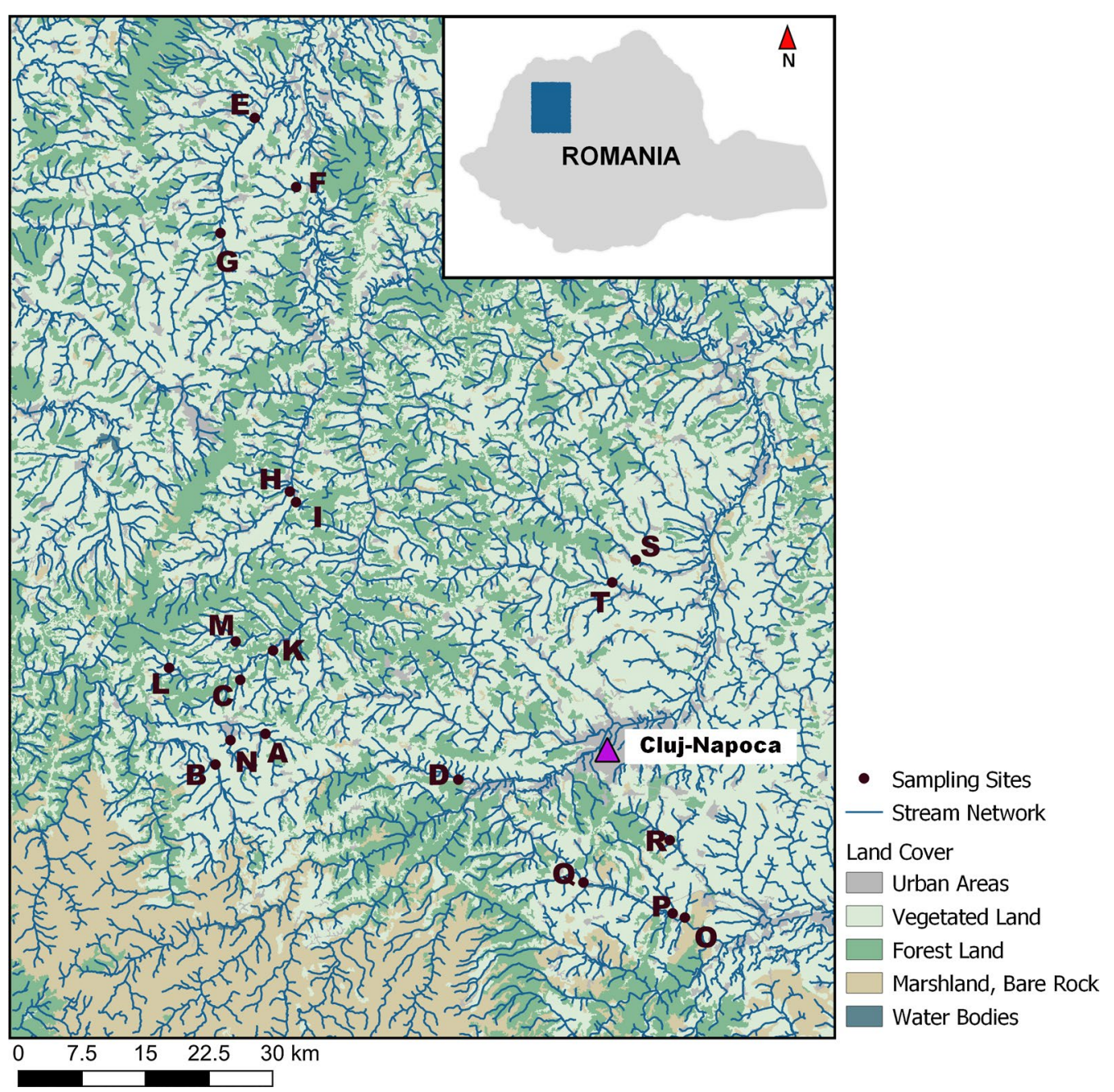

Fig. 1 Stream network of sampling area. Sampling sites labelled from A to T in Central Romania, around Cluj-Napoca [28]

low-intensity agriculture in the catchments and, hence, were expected to provide associated gradients in hydromorphological quality, physico-chemical water quality and in-stream pesticide toxicity (Fig. 1).

\section{Sampling of riparian spiders and their potential prey}

Sampling took place in May and June 2016. At each site, transects of $20 \mathrm{~m}$ along the streams were defined for biological sampling. Tetragnatha sp. and Pardosa sp. were selected (see Additional file 1: Tables S2, S3) after sampling of aquatic and terrestrial prey. The web weaving spider Tetragnatha sp. and the ground-hunting spider Pardosa sp. were selected as they are common riparian spiders with different foraging strategies, which was expected to lead to different responses to changes in aquatic prey availability. Tetragnatha sp. builds webs on debris and vegetation next to the water to primarily capture flying prey [29]. In contrast, Pardosa sp. hunts a broad spectrum of terrestrial invertebrates in the riparian zone and aquatic prey directly from the water surface [30-32]. To reduce variability, where feasible, only adult female spiders were analysed, because adult male spiders may abandon food intake (see details about specimens in Additional file 1: Tables S2, S3). All spiders were hand collected and kept individually in small containers.

We sampled the aquatic invertebrates using aquatic emergence traps [33] with a basal area of $0.25 \mathrm{~m}^{2}$, which were emptied at least once a week. Two traps were placed per stream, each with a bottle trap that was filled with an aqueous solution of $1 \%$ (vol.) Tween ${ }^{\circledR} 80$, a non-ionic detergent, and saturated with sodium chloride (for preservation purposes). As spider tissue needs 1-3 weeks to enrich stable isotope signals from their contributed prey $[2,34]$, we sampled aquatic prey over 3 weeks until 
1 week before spider sampling. Of the species collected in the traps, we selected those for stable isotope analysis that occurred in sufficient numbers and that are known to be prey for the studied spiders [32, 35] (Table 1). Terrestrial prey organisms were sampled once, 3 weeks before the sampling of the spiders. Terrestrial prey was collected with a modified leaf blower (modified STIHL SH86 blower; Stihl). Vegetation and ground were vacuumed within a distance of $0-1.5 \mathrm{~m}$ to the stream 50 times each for $5 \mathrm{~s}$, resulting in a sampled area of approximately $5 \mathrm{~m}^{2}$. The vacuumer gauze bags were transferred to a plastic bag to avoid organisms from escaping. All samples, including the plastic bags, were transported at $\sim 5^{\circ} \mathrm{C}$ and later kept frozen $\left(\sim-18^{\circ} \mathrm{C}\right)$ until sorting, identification and analysis. Spiders were kept up to $12 \mathrm{~h}$ in vessels before freezing to allow for excretion of the gut content.

\section{Preparation of spider and prey samples for stable isotope analysis}

Spiders were identified to species level following Roberts [29]. Where feasible, aquatic and terrestrial prey were identified to genus, family and order and family level, respectively.

For isotope analysis, samples were dried at $60{ }^{\circ} \mathrm{C}$ for at least $24 \mathrm{~h}$. Where size allowed, single organisms were used in the isotope analysis, otherwise multiple individuals of one taxon were pooled to ensure a sufficient amount of material for the analysis. Samples were homogenised and weighted into tin cups (approximately $0.5-1 \mathrm{mg}$ ). Three to five replicates per site and organism group were analysed using a Flash 2000 HT elemental analyser coupled via a ConFlo IV interface to a Delta V Advantage isotope ratio mass spectrometer (Thermo Fisher Scientific). Stable isotope ratios of carbon and nitrogen are presented in conventional $\delta$

\section{Table 1 Origin of the prey organisms, prey groups used in the mixing model and prey groups used in the stable isotope analysis (SIA)}

\begin{tabular}{|c|c|c|}
\hline $\begin{array}{l}\text { Prey origin (aquatic/ } \\
\text { terrestrial) }\end{array}$ & $\begin{array}{l}\text { Prey groups } \\
\text { in mixing model }\end{array}$ & Prey groups used in SIA \\
\hline \multirow[t]{7}{*}{ Aquatic } & Diptera & Empididae \\
\hline & & Chironomidae \\
\hline & & Simuliidae \\
\hline & Ephemeroptera & Ephemeroptera \\
\hline & Trichoptera & Hydropsyche \\
\hline & & Hydroptilidae \\
\hline & & Trichoptera other \\
\hline \multirow[t]{3}{*}{ Terrestrial } & Collembola & Collembola \\
\hline & Hemiptera & Auchenorrhyncha \\
\hline & & Sternorrhyncha \\
\hline
\end{tabular}

notation (\%) relative to their respective international standards (Vienna Pee Dee Belemnite) and atmospheric $\mathrm{N}_{2}$. Repeated analyses of an internal standard (i.e. casein) typically resulted in an accuracy (in terms of \pm standard deviation (SD) of $0.047 \%$ and $0.044 \%$ for carbon and nitrogen, respectively. Prey groups were combined after checking for overlapping of prey samples for mixing models based on stable isotope analysis (SIA) according to taxon and in cases were stable isotope signatures of different insect groups overlapped before the final analysis [36].

\section{Characterisation of environmental parameters and pesticide analysis}

To determine the potential response of aquatic prey to stressors and in turn the propagation of effects to riparian spiders, we recorded the hydromorphological structure and physico-chemical variables at each stream site (Table 2).

The distances to adjacent fields on both sides of the stream were recorded and aggregated into a single value called field distance index (fdi) for each sampling site the $f d i$ as follows:

$$
\begin{aligned}
& \mathrm{fdi}=\frac{\left(\left(1-\frac{X_{\mathrm{L}}}{100}\right)+\left(1-\frac{X_{\mathrm{R}}}{100}\right)\right)}{2} ; \\
& \quad \text { with } x_{\mathrm{L}}=99 \text { if } x_{\mathrm{L}}>99 \text { and } x_{\mathrm{R}}=99 \text { if } x_{\mathrm{R}}>99
\end{aligned}
$$

where $x_{L}$ and $x_{R}$ is the distance to the agricultural field on the left $(\mathrm{L})$ and right $(\mathrm{R})$ side of the stream, respectively. For further details and rationale see [23].

To determine the ratio of land use in the upstream catchment of each sampling site, we overlaid the upstream catchment areas calculated by the ATRIC algorithm [37] with a CORINE land cover vector layer [28]. We used CORINE land cover to distinguish agriculture characterised by arable land, defined as catchment land use type 1 in data analysis, from agriculture with considerable areas of natural vegetation and pastures, defined as catchment land use type 2 in data analysis. These two land use types may loosely be connected to what we qualitatively observed as traditional and industrialised agriculture.

Pesticide sampling was done using passive samplers in the streams adjacent to each sampling site with polydimethylsiloxane (PDSM) sheets and styrene-divinylbenzene (SDB) disks (for details see [23]). The in-stream toxicity of the 53 detected pesticides was assessed using the logarithmic sum of the toxic unit (referred to as sumTU, [38]. The sumTU is based on the $\mathrm{EC}_{50}$ value of the most sensitive freshwater invertebrate species for each pesticide (i.e. the minimum $\mathrm{EC}_{50}$ value), which was 
Table 2 Environmental variables used in data analysis with units and explanation

\begin{tabular}{|c|c|c|c|c|}
\hline \multirow[t]{2}{*}{ Variable } & \multirow[t]{2}{*}{ Unit and explanation } & \multirow[t]{2}{*}{ Loading on SPCA axes } & \multicolumn{2}{|l|}{ Value } \\
\hline & & & Mean & SD \\
\hline Toxicity & Maximum of log sum toxic unit for the most sensitive freshwater invertebrate & Excluded from SPCA & -0.56 & 0.52 \\
\hline $\mathrm{pH}^{\mathrm{b}}$ & & First axis; 0.33 & 8.19 & 0.18 \\
\hline Oxygen ${ }^{b}$ & [\%] dissolved oxygen in the stream & First axis; 0.45 & 75.99 & 8.95 \\
\hline Field distance index & $\begin{array}{l}\text { Weighted distance of streams to agriculturally used fields for right and left site } \\
\text { of the stream, at sampling site }\end{array}$ & First axis; -0.13 & 0.64 & 0.25 \\
\hline Corridor land use meadows & [\%] land cover with meadows within a 200 m distance to the stream & First axis; -0.14 & 52.5 & 25.78 \\
\hline Catchment size & {$\left[\mathrm{km}^{2}\right]$ size of catchment area } & First axis; 0.30 & 76.03 & 67.16 \\
\hline Catchment land use type 1 & [\%] land cover with arable land and permanent crops in the catchment ${ }^{c}$ & First axis; -0.31 & 30.34 & 13.92 \\
\hline Maximal width stream & [m] widest part of the stream at sampling site & First axis; 0.39 & 3.57 & 1.35 \\
\hline Minimal width stream & [m] narrowest part of the stream at sampling site & First axis; 0.42 & 2.28 & 1.23 \\
\hline Riffles & {$[\%]$} & First axis; 0.36 & 41.92 & 28.03 \\
\hline Sulphate $^{a}$ & {$[\mathrm{mg} / \mathrm{L}]$} & Second axis; 0.36 & 64.54 & 33.38 \\
\hline Riparian cover shrubs & $\begin{array}{l}\text { [\%] riparian land covered with shrubs within } 5 \mathrm{~m} \text { to stream along a } 20 \mathrm{~m} \\
\text { transect }\end{array}$ & Second axis; 0.62 & 16.15 & 15.93 \\
\hline Riparian cover meadows & $\begin{array}{l}\text { [\%] riparian land covered with meadows within } 5 \mathrm{~m} \text { to stream along a } 20 \mathrm{~m} \\
\text { transect }\end{array}$ & Second axis; - 0.59 & 25.38 & 25.02 \\
\hline Catchment land use type 2 & [\%] pastures and heterogenous agricultural areas in the catchment ${ }^{c}$ & Second axis; -0.37 & 39.07 & 7.54 \\
\hline \multicolumn{5}{|l|}{ SD standard deviation } \\
\hline \multicolumn{5}{|c|}{ a Compact-photometer PF-12, Macherey-Nagel was used for measurement } \\
\hline \multicolumn{5}{|c|}{ b Multiparameter $\mathrm{pH} / \mathrm{ORP} / \mathrm{EC} / \mathrm{TDS} /$ salinity/DO/pressure/temperature waterproof meter-HI98194, Hanna Instruments was used for measurement } \\
\hline \multicolumn{5}{|c|}{$\begin{array}{l}\text { c CORINE codes from catchment land use } 1 \text { : non-irrigated arable land } 211 \text {, vineyards } 221 \text {, fruit trees and berry plantations } 222 ; \text { CORINE codes from catchment land } \\
\text { use 2: pastures 231, complex cultivation patterns } 242 \text {, land occupied by agriculture with significant areas of natural vegetation and pastures in the catchment area } 243 \\
\text { [28] }\end{array}$} \\
\hline
\end{tabular}

compiled from the Pesticide Property Data Base [39], reported toxicity values in [40] and data from the US EPA ECOTOX data base [40, 41]. A previous comparative analysis of different proxies for exposure showed, that the sumTU was among the indices that yielded the highest relationship with ecological responses [42]. In the analysis, we used the maximum sumTU across four pesticide sampling time points as a proxy for the maximum pesticide pollution, which may influence the export of aquatic prey to the spiders' habitats, in the sampling period. Hereafter, we will refer to the maximum sumTU as toxicity.

\section{Estimation of potential aquatic prey biomass}

The dry biomass $(W)$ of the emerged aquatic insects was used as a proxy for the potential aquatic prey available to spiders. We calculated the potential aquatic prey biomass $W$ using length-mass relationships [43] as:

$$
W=a * L^{b},
$$

where $L$ is length $(\mathrm{mm})$ and $a$ and $b$ are fitted parameters describing the allometric relationship between the dry mass and length. The length $L$ of the aquatic prey and the parameters $a$ and $b$ were taken or estimated from the literature (see Additional file 1: Table S4; $[44,45]$ ).

Finally, the biomass $m$ of aquatic prey per day was calculated as:

$$
m=\frac{\sum W_{i}}{t}
$$

where $t$ is the sum of the number of days per emergence trap per stream during which aquatic prey taxon $i$ was sampled.

\section{Data analyses and statistics}

To identify variables that may explain the potential aquatic prey biomass available at each site, we conducted variable selection using a linear model, given that the response exhibited normal distribution. We conducted stepwise backward model selection and used the Akaike information criterion (AIC) as a model goodness of fit measure [46], corrected for small sample sizes, i.e. corrected AIC (AICc). Similarly, variables that may explain the aquatic contribution to the diet of spiders were identified with a stepwise backward model selection using a linear model for the ground-hunting spider, given that the response exhibited normal distribution, and a generalised linear model (GLM) with binomial distribution, 
as the normal distribution assumption was not met, for the web weaving spider with the AICc as model goodness of fit measure. The aquatic contribution to the spider diet was calculated with the R package MixSIAR [47] (version 3.1.7, run chain length 3,000,000). MixSIAR is based on Bayesian inference and estimates the most likely sources contributing to the spiders' assimilated diets [48]. We used the trophic enrichment factors for terrestrial $\left(0.4 \pm 0.17 \%\right.$ or $\delta^{13} \mathrm{C} ; 2.3 \pm 0.28 \%$ for $\left.\delta^{15} \mathrm{~N}\right)$ and aquatic prey $\left(0.5 \pm 0.19 \%\right.$ or $\delta^{13} \mathrm{C} ; 2.3 \pm 0.24 \%$ or $\left.\delta^{15} \mathrm{~N}\right)$ [49]. To ensure the correct prey organisms were sampled for the spiders, only stable isotope data for the sites where at least $60 \%$ of spiders were inside the mixing polygon were used following [50] (for details see Additional file 1: Tables S3-S6).

Due to loss of emergence traps (three sites for both spiders), absence of web weaving spiders in one site and more than $40 \%$ of spiders' isotopic values in a site lying outside of the mixing polygon (two sites for web weaver, six sites for ground hunter), only 10 sites for groundhunter and 13 sites for web weaving spiders were available for the final analysis.

Toxicity was included as an individual variable in the data analysis, given our focus on the potential relationships of pesticides with spider diets. The intensity of the agricultural land use in the area surrounding each sampling site was not measured directly (see above), but is likely reflected by several measured environmental variables and loosely connected to the different catchment land use types (Table 2). The low ratio of sample size (i.e. number of sites) to the number of explanatory variables prohibited the inclusion of all explanatory variables in the statistical models. To capture most of the information from the variables, we used a sparse principal component analysis (SPCA) to reduce the number of variables in the models and generate orthogonal, i.e. independent, explanatory variables. SPCA improves interpretability through reducing the number of variables that load on an axis at the cost (typically minor) of capturing less of the total variance of all variables [51]. The scores of each sampling site on the two sparse principal component axes were used in the subsequent regression analysis (principal component regression).

The statistical software R [52], with the package effects [53] for graphics, was used for statistical analyses. SPCA was done in $\mathrm{R}$ using the package pcaPP [54]. We provide all computer code and data under https://github.com/ rbslandau/graf_spiderdiet.

\section{Results}

Thirteen variables were captured by the two SPCA axes, which explained $23.9 \%$ and $12.3 \%$, respectively, of the total variance of these environmental data. The first axis was primarily (loading $>0.3$ ) composed of stream conditions such as $\mathrm{pH}$, oxygen concentrations, \% of riffles, stream width and upstream catchment size (Table 2). In addition, it represented the cover with arable and permanent crops in the catchment, indicating high-intensity agricultural land use (Table 2). The field distance index and the cover of meadows within a 200-m corridor of the stream loaded only weakly on the first SPCA axis and will not be considered in interpretation. High values on the first SPCA axis represent a higher $\mathrm{pH}$, higher oxygen, greater width and a higher proportion of riffles in the stream reach as well as a larger catchment. Low values represent a higher amount of catchment land use type 1 , indicating high-intensity agricultural use. To enhance readability, we hereafter refer to the first SPCA axis as agricultural intensity and stream habitat quality gradient. The second SPCA axis was composed of sulphate concentrations in water and the riparian cover close to the streams and land use type 2 , representing pastures and heterogeneous agricultural areas in the catchment, indicating low-intensity land use. Chloride, nitrite and phosphate concentrations in the streams as well as conductivity, the agricultural land use within $200 \mathrm{~m}$ of the stream and shading were not captured by the SPCA axes and consequently omitted from analysis (Table 2 and Additional file 1).

Dry biomass of potential aquatic prey emerging at the study sites ranged from 48.9 to $588.2 \mathrm{mg}$ per trap per day. Diptera made up 1-40\%, Ephemeroptera 5-94\% and Trichoptera $2-90 \%$ of the total aquatic prey biomass. Aquatic prey contributed $40.8-55.4 \%$ (mean $=48 \%$, standard deviation $=3.8 \%$ ) to the diet of web weaving spider and $34.0-53.0 \%$ (mean $=42 \%$, standard deviation $=6.2 \%$ ) to the diet of ground-hunting spiders (details Additional file 1: Table S7). The proportions of aquatic prey in the diets of both spiders were not correlated (Pearson's correlation coefficient $r=0.05$ ).

The best-fit model for emerged biomass of potential aquatic prey only contained the first SPCA axis, i.e. the agricultural intensity and stream habitat quality gradient, which exhibited a positive relation $(\mathrm{AICc}=185.7$, $R^{2}=0.31, n=14$ ). The aquatic proportion in the diet of the web weaver increased with the potential aquatic prey biomass (Fig. 2a) and decreased with the agricultural intensity and stream habitat quality gradient (Fig. 2b), the variables selected in the best-fit model (AICc $=-41.36$, $D^{2}=0.2, n=13$ ). The aquatic diet of the ground hunting spider Pardosa $s p$. was positively related to the in-stream toxicity gradient (Fig. 2c) and negatively related to the second SPCA axis (Fig. 2d), the explanatory variables which were selected for the best-fit model (AICc $=-24.8$, $R^{2}=0.57, n=10$ ). The AICc of all models in stepwise selection can be found in the Additional file 1: Table S8. 

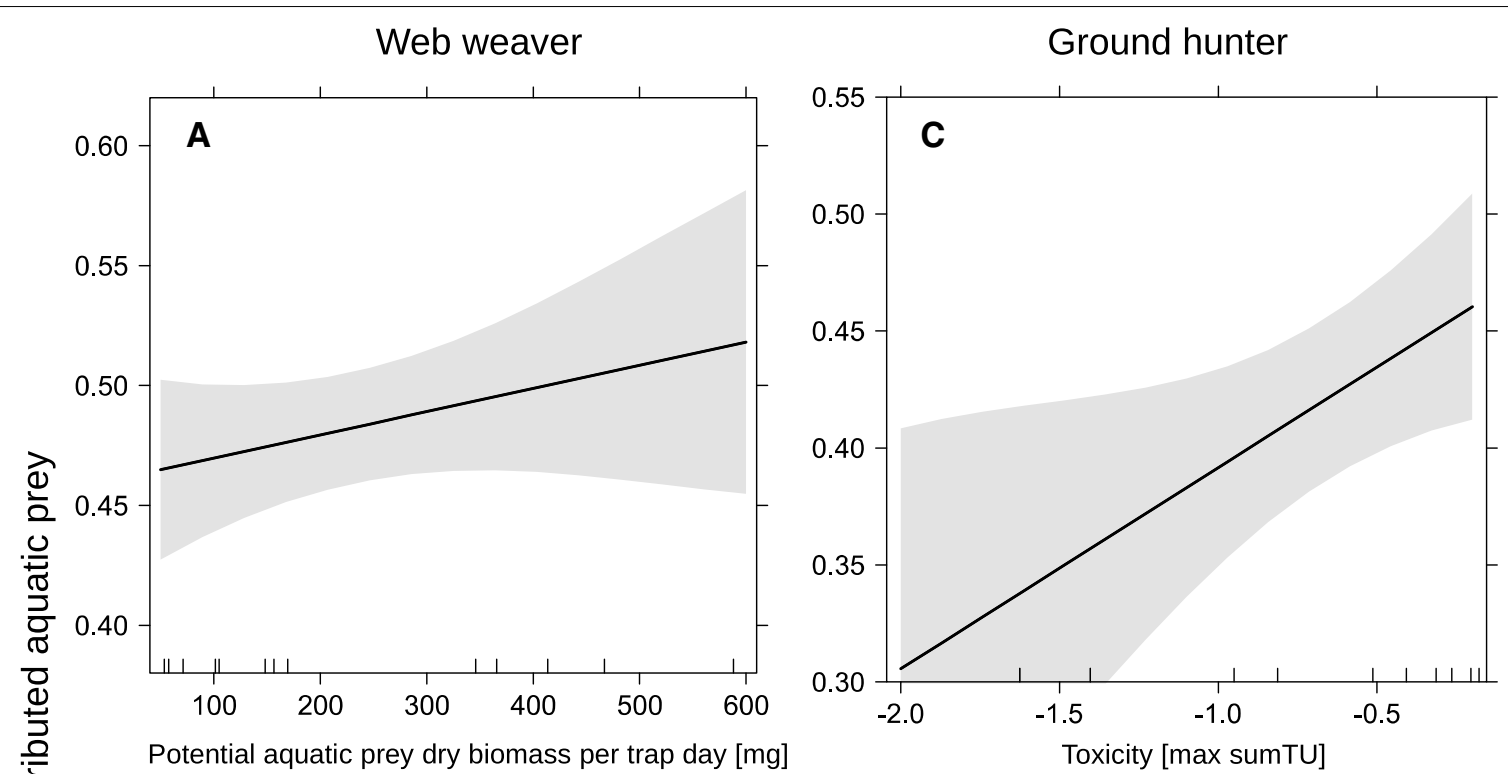

Potential aquatic prey dry biomass per trap day [mg]

Toxicity [max sumTU]
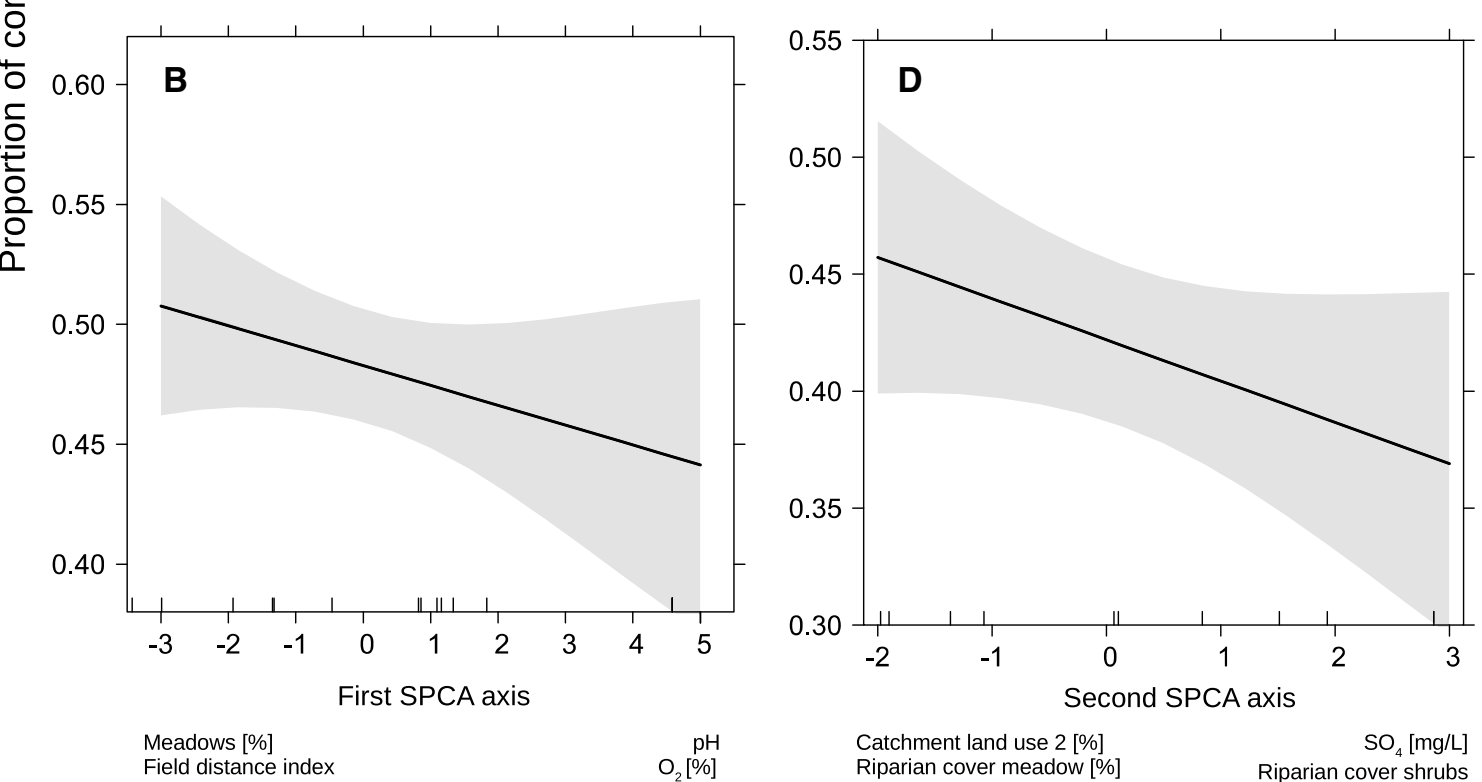

Field distance index

Catchment land use $1[\%]$

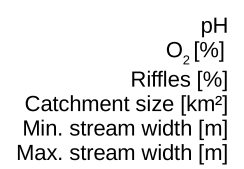

Riparian cover meadow [\%]

Riparian cover shrubs

Catchment size $\left[\mathrm{km}^{2}\right]$

Max. stream width [m]

Fig. 2 Predictor-effect plots [55] for the aquatic contribution to the diet of the web weaver with a aquatic prey dry biomass per trap day, $\mathbf{b}$ the first SPCA axis and the diet of the ground-hunter with $\mathbf{c}$ in-stream pesticide toxicity in terms of logarithmic sum of the toxic unit [max sumTU] and $\mathbf{d}$ the second SPCA axis based on the final models. See Table 2 for loadings of variables composing the SPCA axis, indicating their relevance for the axis. Grey areas indicate $95 \%$ confidence bands for the explanatory variable. Dashes, so-called rugs, show the marginal distribution of an explanatory variable. Note that the plot only displays fitted values for the response based on the partial effect of a predictor with the other predictor held at a typical value. The original values of the response depend on multiple predictors and therefore would be misleading when included in the plot. For details see [56]

\section{Discussion}

\section{Changes in potential aquatic prey biomass in relation} to environmental variables

The biomass of potential aquatic prey was related with a gradient (SPCA axis 1) that primarily represented stream characteristics such as water quality ( $\mathrm{pH}$, oxygen), in-stream hydromorphological conditions (\% riffles) and stream size as well as high-intensity agricultural catchment land use. Hence, the gradient ranged from sites influenced by high-intensity agriculture with lower 
stream oxygen concentrations, and slower flow to sites less influenced by high-intensity agriculture with higher oxygen concentrations, $\mathrm{pH}$ and fast flow sections in terms of riffles. This gradient resembles an agricultural gradient that is known to influence stream macroinvertebrate communities [57, 58]. Moreover, oxygen and fast flow, as present in riffles, are important variables determining habitat quality and consequently invertebrate community composition in stream ecosystems [59]. The finding of higher potential aquatic prey biomass in sites less influenced by high-intensity agricultural land use combined with generally higher habitat quality is in line with previous studies. Agricultural land use in the catchment resulted, relative to forested land use, in smaller and weaker flying aquatic prey (e.g. Diptera) [60]. In terrestrial ecosystems, agriculture has also been related to the loss of flying insect biomass [61]. Riffles correlated positively with the abundance of flying aquatic prey in a study on nine Swedish streams [60].

However, the drivers of changes in the potential aquatic prey biomass are not necessarily the drivers of the diet of riparian predators as shown in a meta-analysis where the aquatic diet contribution of spiders increased with agricultural land use [27]. This is because predators likely exhibit differential feeding preferences and therefore not only the amount but also the composition of the potential aquatic prey is relevant. Furthermore, the contribution of aquatic prey to the diet also depends on the availability of terrestrial prey organisms. The drivers of changes in the potential aquatic prey biomass may also influence the biomass and composition of terrestrial prey organisms. Hence, predicting the diet of riparian predators would require knowledge of the composition and biomass of both aquatic and terrestrial prey as well as of predator feeding preferences. More detailed studies with a longer duration would be required to produce such knowledge. Though we lacked most of this knowledge, we were able to identify drivers of the spider diet based on direct analyses, which we discuss below.

\section{Contribution of aquatic prey to the diet of spiders with different foraging strategies}

The maximum and mean contribution of aquatic prey taxa to the diet of the web weaving spider was higher and the variability and range were narrower compared to the ground-hunter, which matches our expectation. The higher contribution of aquatic prey to web weaving spiders is likely due to the greater reliance of these types of spiders on stream habitats [11]. Most spiders are generalist and opportunist predators and consequently flexible concerning their prey, which is especially pronounced for wolf spiders, such as ground-hunting P. amentata [62]. Although hunting spiders such as $P$. amentata can obtain a substantial amount of resources from aquatic prey, they are less dependent on aquatic prey and less strictly associated with riparian habitats than web weaving spiders $[17,63,64]$. The lower dependence of the ground hunter on riparian habitats was reflected in a lower mean and maximum dietary contribution, most likely as reductions in aquatic biomass can be compensated by contribution of terrestrial prey. The ground-hunter P. amentata is more mobile, and therefore the collected individuals might have fed further away from the stream (less aquatic), whereas web weaving spiders are less mobile during spring time, i.e. the season our study was conducted in [65]. Moreover, we found a wider range and higher variability of aquatic diet contribution for groundhunters reflecting their stronger flexibility in the dietary contribution. This stronger flexibility translates to the expectation that, for ground-hunting spiders, the contribution of aquatic prey to diet responds more strongly to land use than for web weaving spiders, which have a lower capacity to compensate potential losses. However, in our study, we found that both spiders responded to gradients, in terms of SPCA axes, that among other variables represented land use (further discussed below).

The contribution of aquatic prey to the diet differed for both web weaving and ground-hunting spiders between different land uses. Overall, land use likely exhibits multiple direct and indirect effects on riparian predators such as spiders and manipulative field experiments would be more suitable to rigorously test the hypothesis that ground hunters respond stronger to land use than web weavers.

\section{Changes in aquatic prey consumption in relation to environmental variables}

The drivers of the contribution of aquatic prey to the diet of the two spiders differed and only the ground hunter responded to toxicity. The contribution of aquatic prey to the web weavers' diet was positively related with potential aquatic prey biomass (Fig. 2a). This is in line with other studies showing that aquatic prey contribution increases when more aquatic prey is available [16] and reiterates the dependence of these spiders on aquatic prey. The web weavers' diet was also related to the first SPCA axis, representing a gradient of agricultural intensity and stream habitat quality. We suggest that this gradient affected the contribution of the aquatic diet through several direct and indirect paths. First, as discussed above, this gradient affected the potential aquatic prey biomass, representing an indirect effect because the web weavers' diet was directly related to the potential aquatic prey biomass. Second, given that the gradient exhibited independent explanatory power in addition to the potential aquatic prey biomass, the agricultural stressors represented 
by this gradient may have directly affected the spiders. Third, the agricultural stressors represented by this gradient may have directly affected terrestrial prey composition and biomass, thereby indirectly affecting the diet of the web weaver. Overall, although field studies are important to identify the main drivers of populations and communities in real world ecosystems, more controlled conditions would be required to test specific hypotheses regarding the mechanisms (e.g. direct or indirect effects) of the observed patterns.

The diet of ground-hunting spiders also responded to a complex gradient of environmental variables (SPCA axis 2). However, this gradient mainly represented riparian habitat conditions (Table 2), whereas the gradient to which the diet of the web weaver responded mainly represented stream conditions. The contribution of aquatic diet in the ground-hunter increased when the riparian habitat changed from shrubs to meadows.

Moreover, the proportion of aquatic diet consumed by ground-hunting spiders increased with in-stream toxicity. While the proportion of aquatic diet of the ground hunter increased, a follow-up analysis showed that the abundance of ground hunting Pardosa sp. responded strongly negatively to toxicity (GLM, $p=0.002, D^{2}=0.48$, $n=17$ ) (see data from [23]). However, no statistically significant relationship between web weaving Tetragnatha sp. and toxicity was found (GLM, $p=0.150, D^{2}=0.13$, $n=17$ ). A study on insectivorous birds also found a negative response of their abundance to pesticides, which the authors attributed to a decrease in available prey [4]. It is well established that the levels of pesticide toxicity observed in our study can lead to compositional changes in aquatic invertebrate communities as shown in a metaanalysis $[19,66]$ and review [26]. This will in turn affect the composition of emerging insects and riparian predators, where the direction of the effect will depend on predator preferences. However, we are not aware of other studies demonstrating such a response (i.e. the decrease in abundance of a riparian predator but increase in aquatic prey consumption in response to in-stream toxicity) and, as emphasised above, controlled experiments would be required to rigorously test mechanisms underlying the observed pattern. We speculate that in-stream toxicity is a proxy for the general pesticide exposure and that this has directly reduced the abundance of the ground-hunting spiders. Indeed, we found that in-stream pesticide toxicity is a major driver of the riparian spider community composition in our sites [23]. High in-stream toxicity might also have sublethal effects on emerging aquatic insects, making them easy prey for ground-hunting spiders and thus increasing their contribution to the diet of ground-hunter. At the same time, uptake of toxicants by preying on moribund aquatic insects could also explain the decline in ground-hunting Pardosa sp. densities with increasing stream toxicity [23].

As an alternative explanation for the increase of aquatic prey in ground-hunting spiders with increasing in-stream toxicity, the lower abundances of ground hunting spiders along streams with high toxicity may in turn reduce competition for aquatic prey and consequently increase the contribution of aquatic prey in their diets (i.e. "death frees up resources"). However, this explanation contrasts with the fact that a reduction in spiders would also decrease the competition for terrestrial prey. This apparent contradiction may be resolved when taking prey quality into account. Aquatic and terrestrial organisms differ in their quality and compositions [67]. Studies of aquatic prey have mainly considered their quantity and not their quality [68], although nutritional quality of aquatic prey is important for spiders (e.g. immune system, prey capture efficiency) $[69,70]$. Indeed, the quality of aquatic prey organisms can vary [71]. A study suggested that qualitative rather than quantitative (e.g. biomass) differences in prey may have driven responses in terrestrial spiders related with land use in their study [13]. A study in South Africa showed a general net flow of highly unsaturated fatty acids from river to land, even though land-to-river inputs were dominated by biomass [68]. Due to the accumulation of predators at streams $[2,16,72]$ we assume that aquatic prey might be preferred by spiders due to a higher quality. However, we can only speculate on the mechanisms underlying the observed patterns. To rigorously test hypotheses related to underlying mechanisms, we suggest that future studies on the response of spiders to agricultural land use and specifically pesticide gradients should consider i) potential direct effects on abundances and ii) potential indirect effects resulting from direct effects on aquatic and terrestrial prey availability. This will likely require different study designs, i.e. controlled field experiments or mesocosm studies.

\section{Conclusions}

The contribution of aquatic prey to the diet was related to different drivers in two riparian spiders. Partly matching our expectation, in-stream toxicity influenced the abundance of ground hunting Pardosa sp, and the relative contribution of aquatic and terrestrial prey in its diet. However, the web weaver also responded to a gradient of agricultural intensity and stream habitat quality, to which pesticide toxicity may have contributed. This agricultural gradient reduced the biomass of potential aquatic prey, and their contribution to the diet of the web-building spider, but not abundance of the web builder. In general, a reduction in riparian spiders may in turn impact organisms that rely on them as prey such as birds $[4,73]$. Spiders can be affected by 
pesticides in streams via lower quantity of aquatic prey as well as lower quality, but also via an accumulation of the contaminants in spiders and their prey [12, 13, 71, 74]. Further field, mesocosm and laboratory studies on the relationships between prey organisms from a pesticide-contaminated habitat and their predators are needed to differentiate between qualitative and quantitative as well as direct and indirect aspects of crossecosystem effects. This seems particularly important given the worldwide increase in the use of agricultural pesticides [75].

\section{Supplementary information}

Supplementary information accompanies this paper at https://doi. org/10.1186/s12302-019-0282-1.

Additional file 1: Table S1. Coordinates of study sites. Table S2. Stable Isotope signals, and characteristics for web weaving. Table S3. Stable Isotope signals, and characteristics for ground-hunting spiders. Table S4. Estimated length of the prey organisms. Table S5. Environmental variables not captured by SPCA axes and consequently omitted from data analysis used in data analysis with units and explanation. SD = standard deviation. Table S6. Summary statistics for ground-hunting spiders and their prey contribution. Table S7. Summary statistics for web weaving spiders and their prey contribution. Table S8. Contribution of aquatic prey for ground-hunting spiders and web weaving spiders per site. Table S9. AlCc for tested models.

\section{Abbreviations}

AIC: Akaike information criterion; AICc: corrected Akaike information criterion; Fdi: field distance index; max sumTU: maximum summed toxic unit; SIA: stable isotope analysis; sumTU: summed toxic unit.

\section{Acknowledgements}

The authors thank the Department of Environmental Sciences of the Swiss Federal Institute of Aquatic Science and Technology (EAWAG), in particular Bernadette Vogler, Birgit Beck, Heinz Singer and Juliane Hollender, for support with pesticide analysis under their supervision. Jörn Buse helped with site selection and general study design, Sophia Schmidt, Sebastian Marx and Lara Petschick assisted in the field and laboratory. Andreas Hirsch provided technical support with stable isotope analysis and Lucas Streib and Nanki Sidhu created Fig. 1.

\section{Authors' contributions}

NG, MHE and RBS designed the study. NG, RBS, KPB and MC selected sites and KPB and MC assisted with logistics. NG sampled invertebrates, conducted the statistical analysis and drafted the manuscript. KF and NG prepared samples and identified the organisms. VCS conducted the pesticide analytics and created the pesticide gradient. VCS and AS provided the toxicity data. JPZ performed stable isotope analysis. ES, ML, MHE and RBS provided feedback on the statistical analysis. All authors revised the manuscript. All authors gave final approval for publication and agree to be accountable for all aspects of the work in ensuring that questions related to the accuracy or integrity of any part of the work are appropriately investigated and resolved. All authors read and approved the final manuscript.

\section{Funding}

This work has been supported by the Ministerium für Wissenschaft, Weiterbildung und Kultur Rheinland-Pfalz, Germany, ("Research initiative, project AufLand") and by the German Research Foundation (DFG: SCHA 1720/12-1).

\section{Availability of data and materials}

Code and raw data used for this study can be found at https://github.com/ rbslandau/graf_spiderdiet.
Ethics approval and consent to participate Not applicable.

\section{Consent for publication}

Not applicable.

\section{Competing interests}

The authors declare that they have no competing interests.

\section{Author details}

1 iES Landau, Institute for Environmental Sciences, University Koblenz-Landau, Fortstraße 7, 76829 Landau, Germany. ${ }^{2}$ Eußerthal Ecosystem Research Station, University of Koblenz-Landau, Birkenthalstraße 13, 76857 Eußerthal, Germany.

${ }^{3}$ Department of Taxonomy and Ecology, Faculty of Biology and Geology,

Babeș-Bolyai University, 5-7 Clinicilor Str, 400006 Cluj-Napoca, Romania.

Received: 3 September 2019 Accepted: 21 December 2019

Published online: 06 January 2020

\section{References}

1. Graf N, Bucher R, Schäfer RB, Entling MH (2017) Contrasting effects of aquatic subsidies on a terrestrial trophic cascade. Biol Let 13:20170129. https://doi.org/10.1098/rsbl.2017.0129

2. Kato C, Iwata T, Wada E (2004) Prey use by web-building spiders: stable isotope analyses of trophic flow at a forest-stream ecotone. Ecol Res 19:633-643. https://doi.org/10.1111/j.1440-1703.2004.00678.x

3. Paetzold A, Schubert CJ, Tockner K (2005) Aquatic terrestrial linkages along a braided-river: riparian arthropods feeding on aquatic insects. Ecosystems 8:748-759. https://doi.org/10.1007/s10021-005-0004-y

4. Poulin B, Lefebvre G, Paz L (2010) Red flag for green spray: adverse trophic effects of Bti on breeding birds: Bti effects on breeding birds. J Appl Ecol 47:884-889. https://doi.org/10.1111/j.1365-2664.2010.01821.x

5. Boulton AJ, Boyero L, Covich AP et al (2008) Are tropical streams ecologically different from temperate streams? Tropical stream ecology. Elsevier, New York, pp 257-284

6. Freitag H (2004) Composition and longitudinal patterns of aquatic insect emergence in small rivers of Palawan Island, the Philippines. Int Rev Hydrobiol 89:375-391. https://doi.org/10.1002/iroh.200310710

7. Iwata T (2007) Linking stream habitats and spider distribution: spatial variations in trophic transfer across a forest-stream boundary. Ecol Res 22:619-628. https://doi.org/10.1007/s11284-006-0060-6

8. Iwata T, Nakano S, Murakami M (2003) Stream meanders increase insectivorous bird abundance in riparian deciduous forests. Ecography 26:325-337. https://doi.org/10.1034/j.1600-0587.2003.03355.x

9. Edwards ED, Huryn AD (1995) Annual contribution of terrestrial invertebrates to a New Zealand trout stream. NZ J Mar Freshwat Res 29:467-477. https://doi.org/10.1080/00288330.1995.9516680

10. Power ME, Parker MS, Sabo SL et al (2004) River-to-watershed subsidies in an old-growth conifer forest. In: Polis GA, Power ME, Huxel GA (eds) Food webs at the landscape level. The Chicago Press, Chicago and London, pp 217-240

11. Krell B, Röder N, Link M et al (2015) Aquatic prey subsidies to riparian spiders in a stream with different land use types. Limnologica 51:1-7. https ://doi.org/10.1016/j.limno.2014.10.001

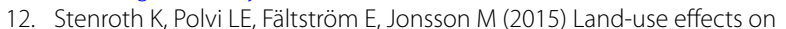
terrestrial consumers through changed size structure of aquatic insects. Freshw Biol 60:136-149. https://doi.org/10.1111/fwb.12476

13. Walters DM, Fritz KM, Otter RR (2008) The dark side of subsidies: adult stream insects export organic contaminants to riparian predators. Ecol Appl 18:1835-1841. https://doi.org/10.1890/08-0354.1

14. Carlson PE, McKie BG, Sandin L, Johnson RK (2016) Strong land-use effects on the dispersal patterns of adult stream insects: implications for transfers of aquatic subsidies to terrestrial consumers. Freshw Biol 61:848-861. https://doi.org/10.1111/fwb.12745

15. Gergs R, Koester M, Schulz RS, Schulz R (2014) Potential alteration of cross-ecosystem resource subsidies by an invasive aquatic macroinvertebrate: implications for the terrestrial food web. Freshw Biol 59:2645-2655. https://doi.org/10.1111/fwb.12463 
16. Kraus JM, Schmidt TS, Walters DM et al (2014) Cross-ecosystem impacts of stream pollution reduce resource and contaminant flux to riparian food webs. Ecol Appl 24:235-243. https://doi.org/10.1890/13-0252.1

17. Collier KJ, Bury S, Gibbs M (2002) A stable isotope study of linkages between stream and terrestrial food webs through spider predation. Freshw Biol 47:1651-1659. https://doi.org/10.104 6/j.1365-2427.2002.00903.x

18. Paetzold A, Smith M, Warren PH, Maltby L (2011) Environmental impact propagated by cross-system subsidy: Chronic stream pollution controls riparian spider populations. Ecology 92:1711-1716. https://doi. org/10.1890/10-2184.1

19. Schäfer RB, von der Ohe PC, Rasmussen J et al (2012) Thresholds for the effects of pesticides on invertebrate communities and leaf breakdown in stream ecosystems. Environ Sci Technol 46:5134-5142. https://doi. org/10.1021/es2039882

20. Fogel MN, Schneider MI, Rimoldi F et al (2016) Toxicity assessment of four insecticides with different modes of action on pupae and adults of Eriopis connexa (Coleoptera: Coccinellidae), a relevant predator of the Neotropical Region. Environ Sci Pollut Res 23:14918-14926. https://doi. org/10.1007/s11356-016-6654-9

21. Gibbs KE, Mackey RL, Currie DJ (2009) Human land use, agriculture, pesticides and losses of imperiled species. Divers Distrib 15:242-253. https:// doi.org/10.1111/j.1472-4642.2008.00543.x

22. Schulz R, Bundschuh M, Gergs R et al (2015) Review on environmental alterations propagating from aquatic to terrestrial ecosystems. Sci Total Environ 538:246-261. https://doi.org/10.1016/j.scitotenv.2015.08.038

23. Graf N, Battes KP, Cimpean M et al (2019) Do agricultural pesticides in streams influence riparian spiders? Sci Total Environ 660:126-135. https:// doi.org/10.1016/j.scitotenv.2018.12.370

24. Fischer J, Hartel T, Kuemmerle T (2012) Conservation policy in traditional farming landscapes: conserving traditional farming landscapes. Conserv Lett 5:167-175. https://doi.org/10.1111/j.1755-263X.2012.00227.x

25. Kovács-Hostyánszki A, Földesi R, Mózes E et al (2016) Conservation of pollinators in traditional agricultural landscapes-new challenges in Transylvania (Romania) posed by EU accession and recommendations for future research. PLoS ONE 11:e0151650. https://doi.org/10.1371/journ al.pone. 0151650

26. Schäfer RB (2019) Responses of freshwater macroinvertebrates to pesticides: insights from field studies. Curr Opin Environ Sci Health 11:1-7. https://doi.org/10.1016/j.coesh.2019.06.001

27. Lafage D, Bergman E, Eckstein RL et al (2019) Local and landscape drivers of aquatic-to-terrestrial subsidies in riparian ecosystems: a worldwide meta-analysis. Ecosphere 10:e02697. https://doi.org/10.1002/ecs2.2697

28. European Environment Agency (2007) CLC2006 technical guidelines. In: European Environment Agency. https://www.eea.europa.eu/publicatio ns/technical_report_2007_17. Accessed 2 Aug 2018

29. Roberts MJ (1996) Collins Field Guide: Spiders of Britain and Northern Europe. Repr. HarperCollins Publisher Ltd., London

30. Graham AK, Buddle CM, Spence JR (2003) Habitat affinities of spiders living near a freshwater pond. J Arachnol 31:78-89. https://doi. org/10.1636/0161-8202(2003)031\%5b0078:HAOSLN\%5d2.0.CO;2

31. Marshall SD, Rypstra AL (1999) Spider competition in structurally simple ecosystems. J Arachnol 1:343-350

32. Nyffeler M (1999) Prey selection of spiders in the field. J Arachnol 27:317-324

33. Cadmus P, Pomeranz JPF, Kraus JM (2016) Low-cost floating emergence net and bottle trap: comparison of two designs. J Freshw Ecol 31:653-658. https://doi.org/10.1080/02705060.2016.1217944

34. Ostrom PH, Colunga-Garcia M, Gage SH (1997) Establishing pathways of energy flow for insect predators using stable isotope ratios: field and laboratory evidence. Oecologia 109:108-113. https://doi.org/10.1007/ s004420050064

35. Nyffeler M, Sunderland KD (2003) Composition, abundance and pest control potential of spider communities in agroecosystems: a comparison of European and US studies. Agr Ecosyst Environ 95:579-612. https:// doi.org/10.1016/S0167-8809(02)00181-0

36. Phillips DL, Inger R, Bearhop S et al (2014) Best practices for use of stable isotope mixing models in food-web studies. Can J Zool 92:823-835. https ://doi.org/10.1139/cjz-2014-0127

37. Bhowmik AK, Metz M, Schäfer RB (2015) An automated, objective and open source tool for stream threshold selection and upstream riparian corridor delineation. Environ Model Softw 63:240-250. https://doi. org/10.1016/j.envsoft.2014.10.017

38. Schäfer RB, Gerner N, Kefford BJ et al (2013) How to characterize chemical exposure to predict ecologic effects on aquatic communities? Environ Sci Technol 47:7996-8004. https://doi.org/10.1021/es4014954

39. Lewis KA, Tzilivakis J, Warner DJ, Green A (2016) An international database for pesticide risk assessments and management. Hum Ecol Risk Assess 22:1050-1064. https://doi.org/10.1080/10807039.2015.1133242

40. Malaj $E$, von der Ohe PC, Grote M et al (2014) Organic chemicals jeopardize the health of freshwater ecosystems on the continental scale. Proc Natl Acad Sci 111:9549-9554. https://doi.org/10.1073/pnas.1321082111

41. U.S. Environmental Protection Agency (2018) ECOTOX User Guide: ECOTOXicology Knowledgebase System Version 4.0

42. Beketov MA, Kefford BJ, Schafer RB, Liess M (2013) Pesticides reduce regional biodiversity of stream invertebrates. Proc Natl Acad Sci 110:11039-11043. https://doi.org/10.1073/pnas.1305618110

43. Sabo JL, Power ME (2002) Numerical response of lizards to aquatic insects and short-term consequences for terrestrial prey. Ecology 83:30233036. https://doi.org/10.1890/0012-9658(2002)083\%5b3023:NROLT $\mathrm{A} \% 5 \mathrm{~d} 2.0 . \mathrm{CO} ; 2$

44. Müller HJ, Bährmann R (2015) Bestimmung wirbelloser Tiere: Bildtafeln für zoologische Bestimmungsübungen und Exkursionen, 7, überarbeitete und ergänzte. Springer, Berlin

45. Schaefer M, Ansorge H, Brohmer P (2010) Brohmer-Fauna von Deutschland: ein Bestimmungsbuch unserer heimischen Tierwelt, 23, durchges. Quelle \& Meyer, Wiebelsheim

46. Akaike H (1974) A new look at the statistical model identification. IEEE Trans Autom Control 19:716-723. https://doi.org/10.1109/ TAC.1974.1100705

47. Stock B, Jackson AL, Ward EJ, Venkiteswaran J (2018) Brianstock/Mixsiar 3.1.9. Zenodo

48. Moore JW, Semmens BX (2008) Incorporating uncertainty and prior information into stable isotope mixing models. Ecol Lett 11:470-480. https:// doi.org/10.1111/j.1461-0248.2008.01163.x

49. McCutchan JH, Lewis WM, Kendall C, McGrath CC (2003) Variation in trophic shift for stable isotope ratios of carbon, nitrogen, and sulfur. Oikos 102:378-390. https://doi.org/10.1034/j.1600-0706.2003.12098.x

50. Parnell AC (2016) simmr: A Stable Isotope Mixing Model

51. Zou H, Hastie T, Tibshirani R (2006) Sparse principal component analysis. J Comput Graph Stat 15:265-286. https://doi.org/10.1198/106186006X 113430

52. R Development Core Team (2011) A Language and Environment for Statistical Computing. the R Foundation for Statistical Computing, Vienna, Austria

53. Fox J, Hong J (2009) Effect displays in R for multinomial and proportionalodds logit models: extensions to the effects package. J Stat Softw. https ://doi.org/10.18637/jss.v032.i01

54. Filzmoser P, Fritz H, Kalcher K (2018) pcaPP: Robust PCA by Projection Pursuit

55. Fox J, Weisberg S (2019) An R companion to applied regression, 3rd edn. Sage Publications Inc, Thousand Oaks

56. Fox J, Weisberg S (2018) Predictor Effects graphics gallery

57. Burdon FJ, Munz NA, Reyes M et al (2019) Agriculture versus wastewater pollution as drivers of macroinvertebrate community structure in streams. Sci Total Environ 659:1256-1265. https://doi.org/10.1016/j.scito tenv.2018.12.372

58. Piggott JJ, Townsend CR, Matthaei CD (2015) Climate warming and agricultural stressors interact to determine stream macroinvertebrate community dynamics. Glob Change Biol 21:1887-1906. https://doi. org/10.1111/gcb.12861

59. Schindler DE, Smits AP (2017) Subsidies of aquatic resources in terrestrial ecosystems. Ecosystems 20:78-93. https://doi.org/10.1007/s1002 1-016-0050-7

60. McKie BG, Sandin L, Carlson PE, Johnson RK (2018) Species traits reveal effects of land use, season and habitat on the potential subsidy of stream invertebrates to terrestrial food webs. Aquat Sci. https://doi.org/10.1007/ s00027-018-0565-4

61. Hallmann CA, Sorg M, Jongejans E et al (2017) More than 75 percent decline over 27 years in total flying insect biomass in protected areas. PLOS ONE 12:e0185809. https://doi.org/10.1371/journal.pone.0185809 
62. Foelix RF (2011) Biology of spiders, 3rd edn. Oxford University Press, Oxford, New York

63. Briers RA, Cariss HM, Geoghegan R, Gee JHR (2005) The lateral extent of the subsidy from an upland stream to riparian lycosid spiders. Ecography 28:165-170. https://doi.org/10.1111/j.0906-7590.2005.04020.x

64. Sanzone DM, Meyer JL, Marti E et al (2003) Carbon and nitrogen transfer from a desert stream to riparian predators. Oecologia 134:238-250. https ://doi.org/10.1007/s00442-002-1113-3

65. Pfister SC, Schäfer RB, Schirmel J, Entling MH (2015) Effects of hedgerows and riparian margins on aerial web-building spiders in cereal fields. J Arachnol 43:400-405. https://doi.org/10.1636/0161-8202-43.3.400

66. van Wijngaarden RPA, Brock TCM, Brink PJ (2005) Threshold levels for effects of insecticides in freshwater ecosystems: a review. Ecotoxicology 14:355-380. https://doi.org/10.1007/s10646-004-6371-x

67. Twining CW, Brenna JT, Hairston NG, Flecker AS (2016) Highly unsaturated fatty acids in nature: what we know and what we need to learn. Oikos 125:749-760. https://doi.org/10.1111/oik.02910

68. Moyo S, Chari LD, Villet MH, Richoux NB (2017) Decoupled reciprocal subsidies of biomass and fatty acids in fluxes of invertebrates between a temperate river and the adjacent land. Aquat Sci 79:689-703. https://doi. org/10.1007/s00027-017-0529-0

69. Fritz KA, Kirschman LJ, McCay SD et al (2017) Subsidies of essential nutrients from aquatic environments correlate with immune function in terrestrial consumers. Freshw Sci 36:893-900. https://doi.org/10.1086/694451
70. Pekár S (2012) Spiders (Araneae) in the pesticide world: an ecotoxicological review. Pest Manag Sci 68:1438-1446. https://doi.org/10.1002/ps.3397

71. Martin-Creuzburg D, Kowarik C, Straile D (2017) Cross-ecosystem fluxes: export of polyunsaturated fatty acids from aquatic to terrestrial ecosystems via emerging insects. Sci Total Environ 577:174-182. https://doi. org/10.1016/j.scitotenv.2016.10.156

72. Henschel JR, Mahsberg D, Stumpf H (2001) Allochthonous aquatic insects increase predation and decrease herbivory in river shore food webs. Oikos 93:429-438. https://doi.org/10.1034/j.1600-0706.2001.930308.x

73. Hallmann CA, Foppen RPB, van Turnhout CAM et al (2014) Declines in insectivorous birds are associated with high neonicotinoid concentrations. Nature 511:341-343. https://doi.org/10.1038/nature13531

74. Richmond EK, Rosi EJ, Walters DM et al (2018) A diverse suite of pharmaceuticals contaminates stream and riparian food webs. Nat Commun. https://doi.org/10.1038/s41467-018-06822-w

75. Bernhardt ES, Rosi EJ (2017) Synthetic chemicals as agents of global change. Front Ecol Environ 15:84-90. https://doi.org/10.1002/fee.1450

\section{Publisher's Note}

Springer Nature remains neutral with regard to jurisdictional claims in published maps and institutional affiliations.

\section{Submit your manuscript to a SpringerOpen ${ }^{\odot}$ journal and benefit from:}

- Convenient online submission

- Rigorous peer review

- Open access: articles freely available online

- High visibility within the field

- Retaining the copyright to your article

Submit your next manuscript at $\boldsymbol{\Delta}$ springeropen.com 